\title{
Malignant Granular Cell Tumor of the Mandible: A Case Report and Review of Literature
}

\author{
Ngoua Essininguele Marie Lysette ${ }^{*}$ Aziz Zakaria, Kabbaj Houda, Fawzi Saad, Karbouch Jinane, Mansouri Hattab Nadia
}

Département of Maxillo-facial Surgery, Cadi Ayyad University, Mohammed VI University Hospital Center, Marrakesh, Morocco

DOI: $10.36347 /$ sjmcr.2021.v09i04.003

| Received: 07.03.2021 | Accepted: 05.04.2021 | Published: 07.04.2021

*Corresponding author: Ngoua Essininguele Marie Lysette

\section{Abstract}

The granular cell tumor, also known as Abrikossoff's tumor, is a rare entity. It was first described by Abrikossoff in 1926. It is a ubiquitous site tumor with a predilection for the cervico-facial region. Their pathogenesis has long been debated. After initially proposing a striated muscle origin, recent studies are in favor of a Schwannian neurogenic origin. Malignant forms have been reported in the literature, with mainly lymph node and pulmonary metastases. We report a case of a malignant granular cell tumor of mandibular localization.

Keywords: Granular cell tumor, Malignant, necrosis, mitoses, prognosis.

Copyright $(\mathcal{C} 2021$ The Author(s): This is an open-access article distributed under the terms of the Creative Commons Attribution 4.0 International License (CC BY-NC 4.0) which permits unrestricted use, distribution, and reproduction in any medium for non-commercial use provided the original author and source are credited.

\section{INTRODUCTION}

The granular cell tumor, also known as Abrikossoff's tumor, is a rare entity. It was first described by the Russian pathologist, Alexeï Ivanovich Abrikossoff in 1926, who named it granulocellular myoblastoma. It is a rare, usually benign tumor, the histogenesis of which has long been controversial. The muscle origin initially suggested was discarded in favor of a nervous origin, or more precisely Schwannian. It is a ubiquitous site tumor with a predilection for the tongue in its intraoral location [1]. Particularly aggressive malignant forms represent less than $2 \%$ of cases, with a poor prognosis. The definitive diagnosis is exclusively histological and immunohistochemical.

\section{ObServation}

An 82-year-old woman, with no particular pathological history, presented with a budding tumor of the oral cavity which had progressed for one year, initially located at the level of the left mandibular angle and gradually increasing in size. Clinical examination revealed facial asymmetry at the expense of the left hemiface in relation to a hard, painless, cheeky swelling with a smooth surface, fixed in relation to the deep and superficial planes. There was a limitation of the mouth opening to $25 \mathrm{~mm}$. The endobucal examination revealed an ulcerative swelling mass, painless, bleeding on contact, infiltrating the labial vestibule beyond the midline, the floor of the mouth in its anterior part without affecting the ventral aspect of the tongue, the internal aspect of the cheek up to 'at the anterior pillar of the palatal tonsil (Figures 1 and 2). Bilateral cervical lymphadenopathy was noted. The general condition was altered with a performance index (OMS) of 3 .

The cervico-facial CT scan was in favor of a tumor process encompassing the mandibular ramus with significant bone lysis, extended to the infratemporal fossa, coming into contact with the lateral wall of the pharynx and infiltrating the prestylar region. There was an endocranial extension of the tumor as well as multiple cervical Lymphadenopathy (Figures 3,4 and 5). The thoraco-abdominal scan revealed the presence of multiple secondary pulmonary nodules. A biopsy was taken. Histological examination showed undifferentiated malignant tumor proliferation, made up of large cells with a vesicular nucleus, most often in mitosis. It carries out syncital, isolated clumps and trabeculae. The stroma was fibrous and inflammatory with numerous osteoclastic-like giant cells. Tumor cell immunostaining was positive for anti-S-100 protein, and anti-CD68. Which led to the diagnosis of malignant granular cell tumor. In view of the advanced stage of the tumor, the patient was referred to oncology for palliative chemotherapy. 


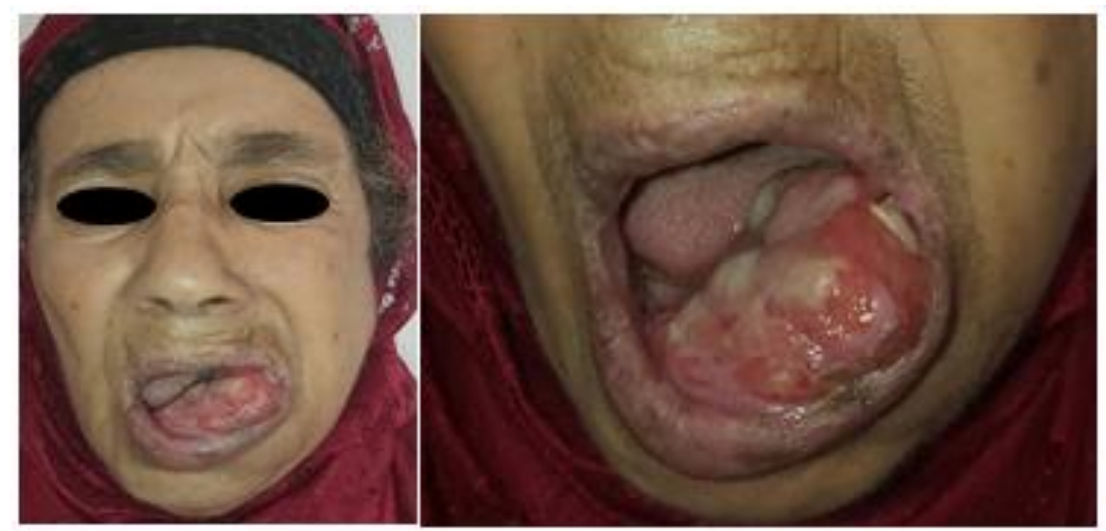

Fig-1, 2: budding tumor of the oral cavity
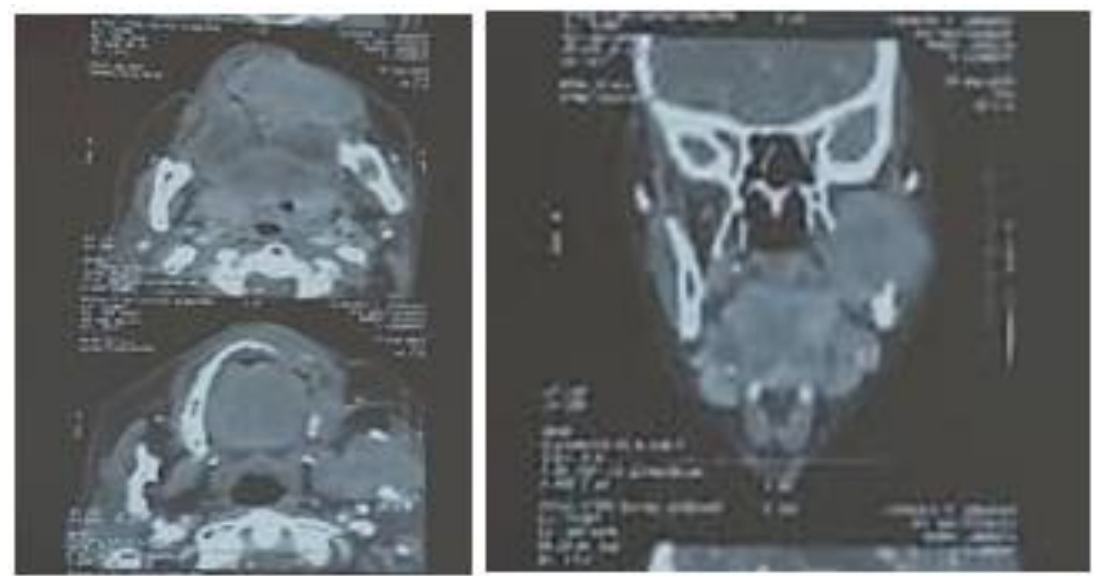

Fig-3, 4: Cervico-facial CT (coronal and axial slices): left mandibular tumor process in the infratemporal fossa

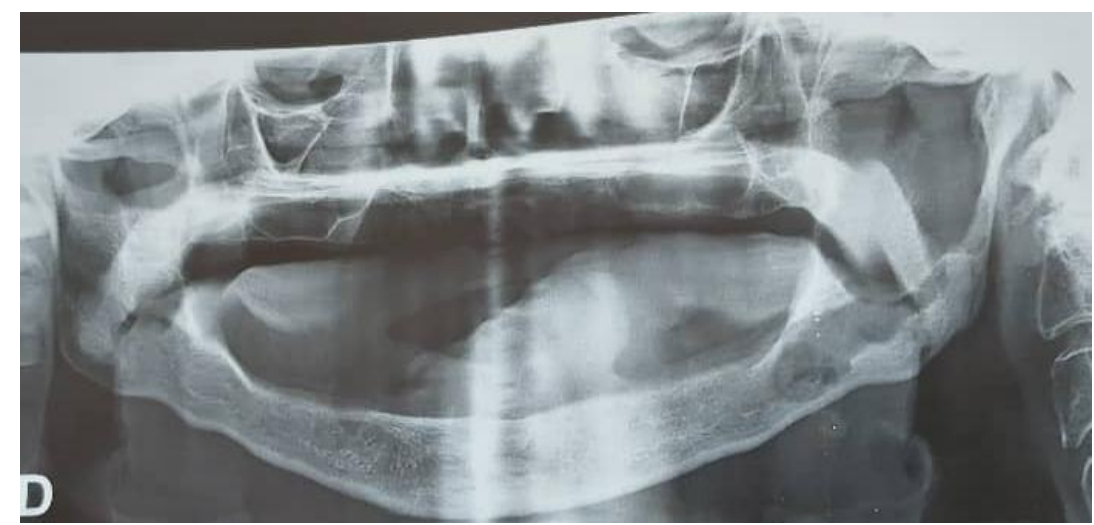

Fig-4: Bone lysis of the ramus and the left mandibular angle

\section{DiscUSSION}

The malignant variant of Abrikossof's tumor accounts for less than $2 \%$ of all granular cell tumors. It is a rare histological entity [2]. It occurs in adults 20 to 60 years old, with a peak in frequency between the fourth and sixth decades with a clear predominance of women. It is rare in children. It is about twice as common in women as in men and in black people [3]. The preferred location is the cervico-facial sphere [4, 5]. However, a few cases of genital, pulmonary, biliary, laryngeal, and mammary and limb locations have been reported in the literature [6-8]. It most often occurs de novo with, however, the possibility of malignant transformation of a benign form; hence the importance of annual monitoring.

Malignant granular cell tumors mainly described in deep visceral locations or in soft tissues. However, they can have a cutaneous or mucous membrane localization. They are clinically suspected in the presence of a lesion larger than $4 \mathrm{~cm}$ in size, the existence of necrotic and / or hemorrhagic areas as well as rapid growth. Because of its clinical polymorphism, only a histological examination coupled with an immunohiscochemical study can confirm the diagnosis. Epidermal hyperplasia, PAS cytoplasm positivity, S100 protein positivity are common to both benign and 
malignant forms. However, given the often atypical nature of the lesion, several diagnostic classifications have been issued. Fanburg-Smith et al. developed a more precise classification with six criteria (tumor necrosis, spindle cells, vesicular nucleus with large nucleoli, mitotic index greater than 2 for ten fields, high nucleocytoplasmic ratio and pleomorphism) The presence of at least three of these criteria makes it possible to consider the tumor to be malignant $[6,9$, 10]. Three of the criteria were found in our case, in addition to the extensive and progressive nature of the tumor process as well as the presence of metastatic pulmonary lesions. Proliferative activity is assessed by the expression of Ki 67 and P 53. A Ki 67 level greater than $10 \%$ is considered by some authors to be an unfavorable prognostic factor.

The differential diagnosis is mainly made with melanoma, malignant tumor of the peripheral sheath, dermatofibrosarcoma, sarcomatoid carcinoma, leiomyosarcoma and angiosarcoma. Hence the interest of performing immunostains, such as Melan-A, Smooth Muscle Actin, CD34, CD31, HMB-45, cytokeratin, CD68 and S100 is highly recommended.

Due to the unfavorable prognosis of the metastatic forms, the malignant forms require an extension assessment to look for secondary lymphatic or systemic locations (lung, liver, bone). Indeed, secondary pulmonary locations are frequently described, and locoregional lymph node invasion accompanies most malignant tissue lesions. This was the case with our patient.

The treatment of choice for malignant granular cell tumors remains surgical excision. Due to its nonencapsulated and infiltrating character, good margins are recommended. Many authors report incomplete resections; in the reported case, the excision brushed the deep edge of the tumor and the lesion, not encapsulated, penetrated deep into the muscles of the tongue $[1,8]$. Thus some authors recommend excision margins of 2 to $3 \mathrm{~cm}$. However, in the oral cavity, tissue preservation is essential; Moh's micrographic surgery may then be indicated. Both adjuvant radiotherapy and chemotherapy have not been shown to be effective but should be considered in inoperable patients.

The prognosis is relatively poor, with a high local recurrence rate $(70 \%$ and an average survival of 45.1 months).

\section{CONCLUSION}

Although rare, malignant granular cell tumor is an aggressive tumor with a poor prognosis, hence the benefit of early diagnosis and management based on surgical excision with safety margins varying from 2 to $3 \mathrm{~cm}$. Due to the recurrent and metastatic potential, rigorous annual monitoring is required.

\section{Contributions of the authors}

All the authors contributed to the medical care of the patient, as well as the writing this article they approved.

\section{REFERENCES}

1. Ayadi L, Khabir A, Fakhfakh I, Abdelmoula MH, Makni S, Sellami Boudawara T. Tumeur à cellules granuleuses. Revue de Stomatologie et de Chirurgie Maxillo-faciale. 1 juin 2008;109(3):158 62.

2. Plantier F. La tumeur à cellules granuleuses ou tumeur d'Abrikossoff. Annales de Dermatologie et de Vénéréologie. 1 mai 2013;140(5):399 402.

3. Nishida $M$, Inoue $M$, Yanai $A$, Matsumoto $T$. Malignant granular cell tumor of the masseter muscle: Case report. Journal of Oral and Maxillofacial Surgery. 1 mars 2000;58(3):345 8.

4. S-100-Negative malignant pulmonary granular cell tumor: A case report | Elsevier Enhanced Reader [Internet]. [cité 19 mars 2021]. Disponible sur: https://reader.elsevier.com/reader/sd/pii/S22130071 1930423X?token=F190B2A9D06D5648D7567336 06AB662AEA08EC5A33D75A96DF9356AE3832 16075677900AC96595B6FB8D593270492565

5. Giant Malignant Granular Cell Tumor (GCT) of the Posterior Mediastinum | Elsevier Enhanced Reader [Internet]. [cité 19 mars 2021]. Disponible sur: https://reader.elsevier.com/reader/sd/pii/S15560864 15334547?token=2071A46E3C13897BD917C5B9 C1DDADEB6C4509F3823B0939F6EAB5795608 FA2FDC6B58A92FF4E47BB5F3F6F498247865

6. Berg JC, Tewari KS, Del Rosario R, Berman ML. Unusual presentation of a malignant granular cell tumor of the pelvis: case report and literature review. Gynecologic Oncology. 1 juill 2003;90(1):224 30.

7. Gavelli A, Clément N, Marmorale A, Ambrosiani N, Nardi F, Perrin H. Tumeur d'Abrikossoff ou tumeur à cellules granuleuses de l'appendice. Gastroentérologie Clinique et Biologique. 1 mars 2005;29(2):2112.

8. Tawfiq N, Sabri S, Saiss K, Bouchbika Z, Benchekroun N, Jouhadi $H$. Tumeur à cellules granuleuses: à propos d'une localisation vulvaire compliquée de métastases pulmonaires. Cancer/Radiothérapie. 1 nov. 2013;17(7):671 4.

9. Fanburg-Smith JC, Meis-Kindblom JM, Fante R, Kindblom L-G. Malignant Granular Cell Tumor of Soft Tissue: Diagnostic Criteria and Clinicopathologic Correlation. The American Journal of Surgical Pathology. juill 1998;22(7):779 94.

10. Nasser H, Ahmed Y, Szpunar SM, Kowalski PJ. Malignant granular cell tumor: A look into the diagnostic criteria. Pathology - Research and Practice. 15 mars 2011;207(3):164 8. 